\title{
Mesothelial metaplasia in European pond turtle, Emys orbicularis (Testudines: Emydidae) infected with Spiroxys contortus (Nematoda: Spirurida)
}

\author{
V. MICLĂUŞ ${ }^{1}$, A. D. MIHALCA ${ }^{2}$, A. F. GAL ${ }^{3 *}$, C. CĂTOI ${ }^{3}$
}

\begin{abstract}
${ }^{1}$ Department of Histology, Faculty of Veterinary Medicine, University of Agricultural Sciences and Veterinary Medicine Cluj-Napoca, Calea Mănăştur 3 - 5, Cluj-Napoca, 400372, Romania; ${ }^{2}$ Department of Parasitology and Parasitic Disease, Faculty of Veterinary Medicine, University of Agricultural Sciences and Veterinary Medicine ClujNapoca, Calea Mănăştur 3 - 5, Cluj-Napoca, 400372, Romania; ${ }^{3}$ Department of Pathologic Anatomy, Necropsy and Veterinary Forensic Medicine, Faculty of Veterinary Medicine, University of Agricultural Sciences and Veterinary Medicine Cluj-Napoca, Calea Mănăştur 3 -5, Cluj-Napoca, 400372, Romania, E-mail: adrianfloringal@yahoo.com
\end{abstract}

\begin{abstract}
Summary
The mesothelium consists of a monolayer of specialized epithelial cells that line the surfaces of the peritoneal, pleural, and pericardial cavities. The present study reports mesothelial changes associated with larval stages of the spirurid nematode Spiroxys contortus in a naturally infected European pond turtle. Between 2002 and 2007, eight European pond turtle, Emys orbicularis were brought for necropsy. In one adult male turtle, necropsy revealed the presence of gastric and mesothelial changes associated with gastric infestation with the nematode Spiroxys contortus. Gastrointestinal samples with gross lesions were collected and processed by paraffin technique for further histological examination. Mesothelial cuboidal to columnar or pseudostratified focal progressive metaplasia was observed in visceral coelomic cavity. Intracytoplasmic acidophilic hyaline inclusions were also observed in metaplastic mesothelial cells, most of them being placed to the apical cell's poles. The significance of our findings is discussed in the light of current knowledge regarding the mesothelial cells.
\end{abstract}

Keywords: coelomic cavity; Emys orbicularis; inclusions; mesothelial metaplasia; Spiroxys

\section{Introduction}

Metaplasia is a reversible or irreversible change in which one adult cell type is replaced by another adult cell type of the same germ line. In the case of epithelia specialized tissue is replaced by less specialized epithelium and is usually the result of chronic irritation (Myers \& McGalvin, 2007).

Infestation with pulmonary nematodes like Crenosoma vulpis and Eucoleus aerophilus are associated with epithelial metaplasia of airways mucosa in foxes (Nevarez et al.,
2005). Some trematodes are also able to produce metaplasia in invertebrates. The marine gastropods Cerithium moniliferum and Peristernia australiensis infected with Lobatostoma manteri develop metaplastic changes in the epithelium of the digestive canaliculi (Rohde \& Sandland, 1973). Another marine gastropod, Batillus cornutus has been found with metaplasia of the epithelium covering the renal coelom (Shimura, 1980). Such metaplasias are probably the mildest response of the peritoneum to irritation (i.e. by parasites) but may also be a response to estrogen (Julian, 1985)

Generally, most of the helminth parasites found in the peritoneal cavity of vertebrates are only transiting during their migration to another organ in the host (i.e. Fasciola, strongyles of equines etc.). Nevertheless, several larval and adult helminths inhabit the abdominal cavity. Larval forms of some cestodes occur as bladder worms (i.e. Taenia hydatigena, T. taeniaeformis etc.) or strap-like bodies or nodules (i.e. Ligula, Mesocestoides) in the body cavity of various vertebrate groups. Larval forms of acanthocephalans are also commonly reported, mainly in wild micromammals and reptiles. Among nematodes, larval stages (i.e. Eustrongylides, Anisakis etc.) or adults (Setaria, Diplotriaena) can occasionally be found in the peritoneum of their respective hosts (Anderson, 2000).

The European pond turtle, Emys orbicularis is host for numerous nematode species (Baker, 1987). Their life cycle often involves the migration of larvae through various tissues inducing mechanical, irritative and toxic actions (Mihalca et al., 2007). The present study reports mesothelial changes associated with larval stages of the spirurid nematode Spiroxys contortus in a naturally infected European pond turtle, with detailed histological description of the processes. 


\section{Materials and methods}

Between 2002 and 2007, eight European pond turtle, Emys orbicularis were brought for necropsy to the Department of Pathology, Faculty of Veterinary Medicine Cluj-Napoca, Romania. The animals were in fresh stage and originated from Danube Delta (Tulcea Country, Romania) being found drowned in fishing nests. During complete necropsy, at gross examination of the stomach we have noticed the presence of nematodes in all the turtles. The nematodes were collected in $70 \%$ ethanol and submitted to the Department of Parasitology for specific identification (morphological keys and descriptions by Mihalca, 2007). In one (an adult male) of the eight turtles, at the stomach level we have noticed the presence of gross lesions (focal whitish spots and thickening of the gastric wall). From sections of the stomach wall and from the gastric and intestinal serosa with evident macroscopic lesions, small pieces (cca. $0.5 \mathrm{~cm}$ ) were fixed in neutral $10 \%$ buffered formalin. Tissues were subsequently embedded in paraffin, sectioned at $5 \mu \mathrm{m}$, and stained with Goldner's trichrome and Periodic Acid Schiff (PAS) methods.

\section{Results}

At gross necropsy, we have noticed focal whitish spots in coelomic cavity and in gastric and intestinal serosa, and mucosal gastric erosions. The focal whitish spots had a few millimeters in diameter $(<0.4 \mathrm{~cm})$ on the serosal surface. The gastric gross findings were present as punctuate erosions $(<0.2 \mathrm{~cm})$ scattered over the mucosa, especially of the fundus. In the stomach lumen, white nematodes of about $2-3 \mathrm{~cm}$ in length were observed. They were subsequently identified in the Department of Parasitology as adults of Spiroxys contortus.

Histopathological examination revealed the presence of two types of lesions: mesothelial metaplasia and fibroplasia. Histological sections in the stomach wall confirmed the presence of adult and larval nematodes (Fig. 1). The severity of proliferative lesions was more pronounced in the serosa, being characterized by a significant hypertrophy and fibroplasia. Mononuclear cells (i.e. macrophages

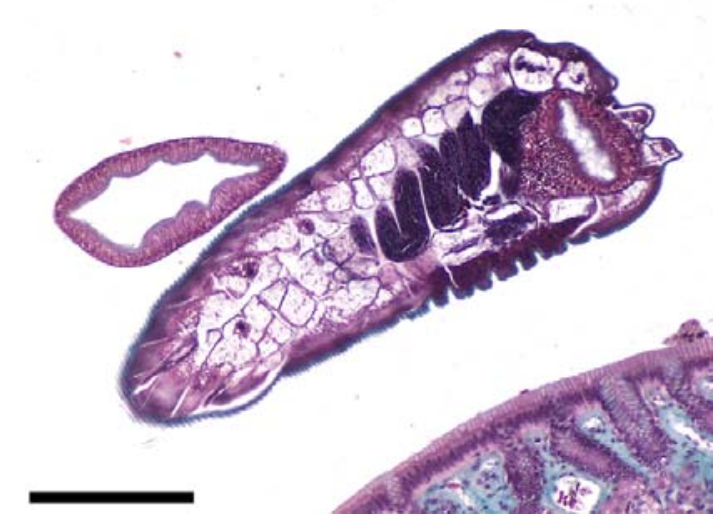

Fig. 1. Adult and larva of Spyroxis contortus in the gastric lumen of Emys orbicularis (Goldner's trichrome). Bar $=500 \mu \mathrm{m}$

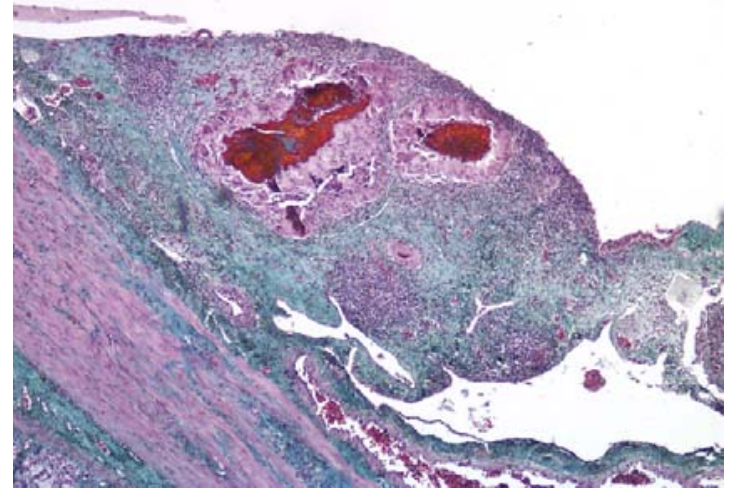

Fig. 2. Fibroplasia and granulomas in the gastric serosa of Emys orbicularis containing larvae of Spyroxis contortus bordered by macrophages, multinucleated giant cells and heterophils (Goldner's trichrome). Bar $=200 \mu \mathrm{m}$

and lymphocytes) represented the main cellular population in the serosal lesions. These chronic proliferative inflammatory reactions were present in all areas of the gastric and ligamentary serosa, including the omentum (mainly in the vicinity of its insertion to the great curvature of the stomach). Intense fibroplasia induced hypertrophy of gastric serosa and omental ligament. In some areas of the serosa, various stages of granulomas, some containing nematode larvae, were present (Fig. 2).

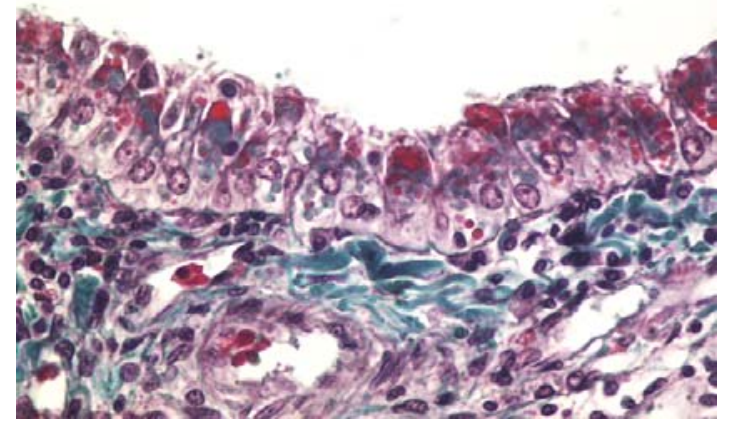

Fig. 3. Mesothelial metaplasia characterized by pseudostratified epithelium from gastric ligaments of Emys orbicularis

with numerous intracytoplasmic acidophilic hyaline inclusions (Goldner's trichrome). Bar $=50 \mu \mathrm{m}$

Mesothelial metaplasia was noticed in various parts of the visceral coelomic serosa. The focal metaplasia consisted in cuboidal to columnar change of mesothelial cells that line coelomic cavity. Furthermore, in some areas the aspect of mesothelial epithelium was pseudostratified (Fig. 3). The majority of mesothelial cells that suffered progressive cuboidal, columnar or pseudostratified metaplasia had intracytoplasmic (PAS negative) acidophilic hyaline inclusions by variable size (Fig. 4). Some inclusions had indistinct to irregular borders, placed usually at the apical pole of the cells.

In some regions of the gastric serosa, massive desquamation following mesothelial metaplasia has been observed. 


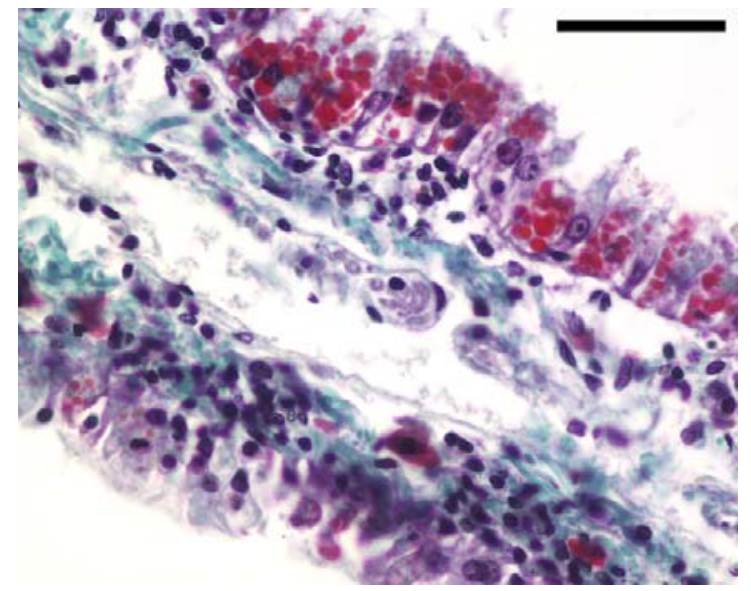

Fig. 4. Intracytoplasmic acidophilic hyaline inclusions in metaplastic mesothelial cells from gastric omentum of Emys orbicularis; acidophilic inclusions are placed to the apical cell poles (Goldner's trichrome). Bar $=50 \mu \mathrm{m}$

Associated to the chronic granulomatous process, the adjacent serosal mesothelial cells become activated, showing a marked pleomorphism and acidophilic intracytoplasmic inclusions or intense basophilic staining. In some mesothelial cells, the nucleus appeared darker with prominent nucleoli and increased nuclear-cytoplasmic ratio. In some other cells, the nucleus was pyknotic. Several activated mesothelial cells were binucleated with cytoplasmic vacuoles and engulfed particles. Mesothelial cell clusters budded off into the coelomic cavity. In some areas with metaplasia, necrotized mesothelial cells were desquamated leaving a denuded basal lamina and cellular debris (Figs. 5 and 6). Below denuded basal lamina intense fibroplasia occurred, causing hypertrophy of gastric serosa.

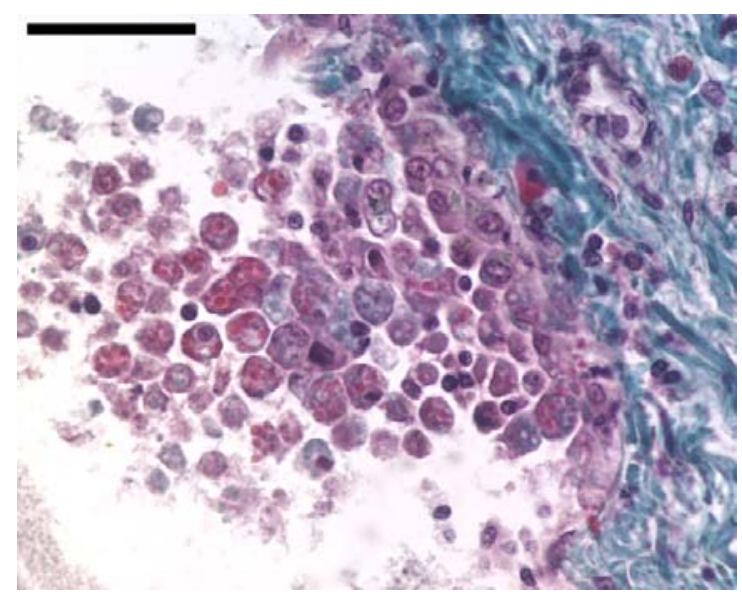

Fig. 5. Mesothelial hyperplasia - mononucleated and binucleated mesothelial cells, focal mesothelial desquamation and denudation of basal lamina of tunica serosa from the gastric wall of Emys orbicularis (Goldner's trichrome). Bar $=50 \mu \mathrm{m}$

\section{Discussion}

Contrary to older believes, mesothelial cells are not passive cells, playing a dynamic active role in peritoneal homeostasis and immunoregulation (Yung \& Chan, 2009). Histologically, the peritoneum consists of a single serosal lining layer of mesothelial cells placed on a basement 106 membrane and a submesothelial layer of connective tissue, which is innaparent in some places (i.e. liver surface) and abundant in other places (i.e. mesenteries) (Julian, 1985). The mesothelial cells vary from squamous to low cuboidal epithelium with single small round nucleus. The cells bear surface microvilli, more abundant on the visceral than on the parietal surface. Microvilli may have a role in retaining secretory hyaluronate-based lubricants. Tight junctions and desmosomes are discontinuous in the surface layer, allowing the diffusion across the membrane (Mutsaers, 2002). Metaplasia of mesothelium is commonly cited. Simple me-

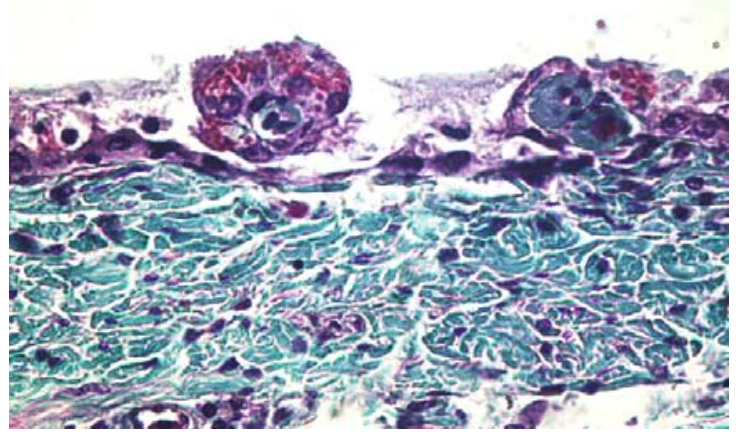

Fig. 6. Desquamated mesothelial cells in the gastric serosa of Emys orbicularis; mesothelial cell clusters which bud off into the coelomic cavity and serosal fibroplasia (Goldner's trichrome). Bar $=50 \mu \mathrm{m}$

taplasia occurs in cases of hydroperitoneum or when alteration to surface contours of organs produces clefts or valleys in which fluid movement is slow. In these cases, mesothelial cells become cuboidal, columnar or may produce hyperplastic nodules. Papillary hyperplasia of mesothelium is frequent in chronic forms of peritonitis (Julian, 1985).

Parasitic infections are also known to induce peritoneal hyperplastic alterations of mesothelium. Coelomic parasites (e.g. larval forms of cestodes like plerocercoids, "Tetrathyridium" or "Sparganum") induce metaplasia to a cuboidal or columnar type resembling epithelium (Julian, 1985). In reptiles, the hypertrophy and proliferation of mesothelial cells have been observed in viral infections with paramyxoviruses in caiman lizards (Dracaena guianensis) (Jacobson et al., 2001).

Granulomatous inflammation and activation of mesothelial cells have been also observed following intraperitoneal implants that generate chronic focal irritation (hormonal implants or implant transmitters) (Goodwin \& Grizzle, 1991; Gray et al., 2005). Goodwin et al. (1991) describe a granulomatous inflammation and monstrous giant cells in response to intraperitoneal hormone implants in channel catfish (Ictalurus punctatus). Gray et al. (2005) describe the coelomic response of implant transmitters in a common amphibian (Bufo cognatus). Coelomic response to the transmitters was represented by a thin transparent connective tissue capsule around all transmitters, which is a typical histological response to local trauma as well as constant 
irritation induced by implants (Gray et al., 2005).

Most detailed reports on mesothelial metaplasia are in humans. Pathogenic significance of hypertrophic mesothelial cells has been assessed in peritoneal effluent in humans but also in ex vivo human peritoneal cell cultures (Bajo et $a l .$, 2004). Although the presence of hypertrophic mesothelial cells in peritoneal effluent has been considered a marker for peritoneal sclerosis (Yamamoto et al., 1998), other authors have found no remarkable functional abnormalities suggestive of severe peritoneal damage (Izumotani et al., 2001). However, Bajo et al. (2004) conclude that the presence of hypertrophic mesothelial cells is not necessarily a marker of sclerosing peritonitis and that such cells may be observed in cultures from new peritoneal effluent patients with no peritoneal function abnormalities. Moreover, under the influence of inflammation and peritonitis, mesothelial cells can undergo epithelial to mesenchymal transdifferentiation, a complex and reversible process that provide the cells with a migratory, invasive fibroblastic phenotype (Yáñez-Mó et al., 2003).

In mammals, mesothelial cells have been shown to secrete several molecules such as cytokines, growth factors, matrix proteins and intracellular adhesion molecules. This shows that mesothelial cells play a critical role as immunomodulators during peritoneal injury and inflammation (Mutsaers, 2002; Yung \& Chan, 2009). In fact, as observed earlier in our case, cytoplasmic acidophilic inclusions from the apical poles of the activated mesothelial cells may reveal a degree of synthesizing activity that might regulate and control peritoneal reaction. As previously shown for mammals, mesothelial cells of lower vertebrates may mediate the inflammatory processes from the coelomic cavity.

\section{References}

ANDERSON, R. C. (2000): Nematode Parasites of Vertebrates: Their Development and Transmission. $2^{\text {nd }}$ Edition, Wallingford, England, CABI Publishing, 650 pp.

Bajo, M. A., Delpeso, G., Castro, M. A., Cirugeda, A., CAstro, M. J., Olea, T., Costero, O., SÁnchez-Tomero, J. A., DÍAZ, C., SElgAS, R. (2004): Pathogenic significance of hypertrophic mesothelial cells in peritoneal effluent and ex vivo culture advances. Perit. Dial. Int., 20: 43 - 46

BAKER, M. R. (1987): Synopsis of the nematode parasitic in amphibians and reptile. St. John's, Nfld., Canada, Memorial University of Newfoundland, Occasional papers in biology, no. 11, pp. $1-325$

Goodwin, A. E., Grizzle, J. M. (1991): Granulomatous inflammation and monstrous giant cells in response to intraperitoneal hormone implants in channel catfish (Ictalurus punctatus). J. Comp. Pathol., 104: 147 - 160. DOI: 10.1016/S0021-9975(08)80098-9

Gray, M. J., Miller, D. L., Smith, L. M. (2005): Coelomic Response and Signal Range of Implant Transmitters in Bufo cognatus. Herpetol. J., 36(3): 285 - 288
IzUmotani, T., Ishimura, E., YAmamoto, T. (2001): Correlation between peritoneal mesothelial cell cytology and peritoneal histopathology with respect to prognosis in patients in continuous ambulatory peritoneal dialysis. Nephron., 89: 43 - 49. DOI: 10.1159/000046042

JaCobson, E. R., Origgi, F., Pessier, A. P., LAMirande, E. W., Walker, I., Whitaker, B., Stalis, I. H., NordhaUSEN, R., OWens, J. W., Nichols, D. K. (2001): Paramyxovirus infection in caiman lizards (Draecena guianensis). J. Vet. Diagn. Invest. 13: 143 - 151. DOI: 10.1177/104063870101300208

JULIAN, R. J. (1985): The peritoneum, retroperitoneum, and mesentery. In: JubB, K. V. F., Kennedy, P. C., PALMER, N. (Eds) Pathology of domestic animals. $3^{\text {rd }}$ Edition, Volume 2. Orlando, Florida, Academic Press, Inc., pp. 330 - 343.

Mihalca, A. D., Gherman, C., Ghira, I., Cozma, V. (2007): Helminth parasites of reptiles (Reptilia) in Romania. Parasitol. Res. 101(2): 491 - 492. DOI: 10.1007/s00436-007-0486-y

MiHalCA, A. D. (2007): Parasitic fauna of free-ranging European pond turtle (Emys orbicularis), sand lizard (Lacerta agilis) and grass snake (Natrix natrix) in Romania. $\mathrm{PhD}$ thesis, Romania, Cluj-Napoca: University of Agricultural Sciences and Veterinary Medicine

MutsaERS, S. E. (2002): Mesothelial cells: their structure, function and role in serosal repair. Respirology. 7: 171 191. DOI: 10.1046/j.1440-1843.2002.00404.x

Myers, R. K., McGalvin, D. M. (2007): Cellular and tissue responses to injury. In: MCGALvin, D. M. (Ed) Pathologic basis of veterinary disease. $4^{\text {th }}$ Edition, St. Louis: Mosby Elsevier, pp. 3 - 62

NevÁrez, A., LóPez, A., Conboy, G., Ireland, W., Sims, D. (2005): Distribution of Crenosoma vulpis and Eucoleus aerophilus in the lung of free-ranging red foxes (Vulpes vulpes). J. Vet. Diagn. Invest. 17(5): 486 - 489. DOI: 10.1177/104063870501700516

ROHDE, K., SANDLAND, R. (1973): Host-parasite relations in Lobatostoma manteri Rohde (Trematoda: Aspidogastrea). Parasitol. Res. 42(2): 115 - 136. DOI: 10.1007/BF00 329789

SHIMURA, S. (1980): Histopathological effects of the adult digenetic trematode Proctoeces ichiharai on the kidney of top shell Batillus cornutus. Helgol. Mar. Res. 34(1): $85-$ 90. DOI: 10.1007/BF01983543

Yamamoto, T., Izumotani, T., Otoshi, T., Kim, M. (1998): Morphological studies of mesothelial cell in CAPD effluent and their clinical significance. Am. J. Kidney Dis. 32: 946 - 952. DOI: 10.1016/S0272-6386(98)70068-X

Yanez-Mo, M., Lara-PezzI, E., Selgas, R., RamireZHuEsCA, M., DOMINGUEZ-JiMENEZ, C., JiMÉNEZHefFernan, J. A. (2003): Peritoneal dialysis and epithelial-to-mesenchymal transition of mesothelial cells. New. Engl. J. Med. 348: 403 - 413

YUNG, S., CHAN, T. M. (2009): Intrinsic cells: mesothelial cells-central players in regulating inflammation and resolution. Periton. Dialysis. Int. 29(2): $21-27$

ACCEPTED FEBRUARY 22, 2013 